We have gone on to positions of national prominence in academia, clinical medicine, industry, and government - to chair 14 academic departments, to become Deans of 7 medical schools and senior executives of 9 academic health systems and universities, to assume very senior positions in industry at 4 international corporations, and to take on 4 very senior posts in the federal government. Twenty of Bill's recruits have been elected to the Institute of Medicine, 2 to the National Academy of Sciences (including 1 new member this year), and 48 to the AAP (including 3 new members this year). And this accounting misses the many who have gone on to other splendid and productive careers in each of these domains.

For over three decades in positions of leadership and trust, Bill always planted next year's crop of rice, never forgetting that the real task was to grow the next generation. Many in our profession are in
Table 1

Selected honors for William N. Kelley, M.D.

- President, American Federation for Clinical Research

- President, American Society for Clinical Investigation

- President, American College of Rheumatology

- Chairman, American Board of Internal Medicine

- Elected to IOM; served on its Council

- Elected to American Academy of Arts and Sciences

- Elected to American Philosophical Society

- Robert H. Williams Award, APM

- David E. Rogers Award, AAMC

- John Phillips Memorial Award and Medal, ACP

- National Medical Research Award, National Health Council

- Emory Medal, Emory University

- Gold Medal, American College of Rheumatology

his debt, and we all thank him for what he passed on to us.

It is my great honor, on behalf of the William N. Kelley.

\title{
2005 Association of American Physicians Kober Medal Acceptance of the 2005 Kober Medal
}

William N. Kelley, M.D.

$T_{h}$ hank you, Ed, for those wonderful comments and thank you, Francis, for your very special homegrown entertainment. Clearly, it has been people like the two of you who have contributed so much to make my professional career so immensely enjoyable.

Thanks also to the officers and councilors of the AAP for selecting me to receive the Kober Medal this year, certainly a signal event in my professional life. I have been sitting in the audience for virtually all of the Kober Medal presentations since 1966, nearly 40 years ago. I have enjoyed learning more about so many of my professional heroes, mentors, and colleagues through these many years. To have my name added to that list of legends of American medicine today is truly an unbelievable experience. Again, my deepest appreciation.

Before I go further, I would like to recognize my family. One takes great pride in one's

This article is adapted from a presentation at the ASCI/AAP Joint Meeting, April 15-17, 2005, in Chicago, Illinois, USA

Address correspondence to: William N. Kelley, University of Pennsylvania School of Medicine, 757 BRB II/III, 421 Curie Boulevard, Philadelphia, Pennsylvania 191046160, USA. Phone: (215) 573-9953.

Citation for this article: J. Clin. Invest. 115:2952-2953 (2005). doi:10.1172/JCI26872. professional accomplishments and successes, and I certainly do. However, one's feelings, love, and devotion to family go far beyond one's life's work. So, I am especially pleased that most can be here today, including my wife of 45 years and best friend, Lois, 3 of our 4 adult children with their spouses, 2 wonderful foster parents, and 8 of our 9 grandchildren, along with 1 additional grandson here in utero. Would all of you please stand? We dearly miss our oldest daughter, Paige, who is institutionalized because of her severe mental illness and our oldest grandson, Jamie, who is severely retarded, mentally and physically, due to cytomegalovirus contracted in utero. Most families must deal with personal tragedy and sadness in their lives and ours is no exception. We are using this weekend to enjoy each other, and my warmest thanks to each of them for being here.

There are others I would like to thank in the time I have available. Perhaps first and foremost, I want to thank the many with whom I have worked closely over the years. Many are professional colleagues with whom I have interacted in innumerable settings throughout the world. Some are individuals that I have had an opportunity to recruit as faculty in one of the three great institutions where I have had an opportunity to serve. A few, who are in some ways most meaningful to me, are those with whom I have had a chance to work in the laboratory. So much of the learning and mentoring I have received, as well as the enjoyment and pride I have felt, comes from the rich experience of working with so many truly outstanding people at every level. We learn from them, they help us mature in our thinking, and they provide incredible personal and professional satisfaction as they succeed in their careers. One evolves from the joy of discovery and getting one's work published in Science, the JCI, or NEJM, to even greater excitement and pride when one of your mentorees makes an important discovery, achieves important recognition, or assumes a major leadership position.

I would like very much to be specific about dozens of these very special colleagues in my life, many of whom are in the audience today. Given the practical constraints of this presentation, however, I will narrow the list to 5 senior physicians at the very top of that long list, who I would like to recognize and thank.

The first on the list is my late father, Dr. Oscar Lee Kelley. In the mid- to late 1940s, following his return from overseas duty with the Air Corps in World War II, he re-established his practice of cardiology in Palm 
Beach. On weekends, holidays, and in the summer, he would take me with him on his morning routine of house calls and hospital rounds. Sometimes, I would have to wait in the nursing station or in the car, initially a Model A Ford, I might add, while he attended to his patient. Usually, however, he would take me with him so I could see him in action and meet the patients and their families. The immense satisfaction of helping people as well as that warm feeling of appreciation from the grateful patient was my introduction to medicine and will be forever with me. Indeed, I can never remember considering a career other than medicine. As an aside, I remember vividly the gifts of oranges, tomatoes, eggs and even mangos that seemed to be part of his daily collection. Given the primitive conditions of some of the homes we entered in rural Palm Beach County, I strongly suspected that, in some cases, these gifts represented full payment for his services. As I chose to pursue an academic career, I believe he was proud of me, but in the later years he would always point out, after introducing me to his friends, colleagues, and patients, that he was the real Dr. Kelley. I guess this was somewhat akin to my mother's recurring question asking when I would complete my training and get a real job.

In my early clinical training, there is one individual who stands out as critical to my career development. That is, of course, Kober Medalist Dr. Donald Seldin. Dr. Seldin was very close to his house staff, basically meeting with them every day in several different settings. Hence, I came to know him well during even my initial weeks as an intern in medicine at Parkland Memorial Hospital in 1963. I not only learned a lot of medicine from him, I liked his leadership, his commitment to excellence, and his interest in helping people, such as myself. Dr. Seldin encouraged me to apply to the NIH for a position and he and a junior colleague of his, and good friend of ours, Dr. Daniel Foster, were critical in helping me to be offered a position there. Dr. Seldin's support and direction clearly changed my life - from a plan to practice on South County Road in Palm Beach with my Dad to an opportunity to go to the NIH, where the excitement and satisfaction of my research experience were to dramatically change my career goals.

Though I was unaware of it at the time, I learned from Don Seldin the importance of supporting and mentoring the house staff. In addition, I learned the importance of recruiting top young stars to the faculty which he did so well in his era at Southwestern and, indeed, I even learned from him how to do it.
At the NIH, I had the opportunity to work with my first real research mentor, Dr. Jay Seegmiller. Jay Seegmiller catalyzed completion of the dramatic turn in my career path. Jay taught me how to do science with an emphasis on absolute integrity. I also recall well the many times my habit of working through the night would overlap with his characteristic pre-dawn arrival. This allowed us to have frequent spontaneous and private lab meetings at dawn's first light. It was the joy of discovery which I experienced with Jay that solidified a research career in the future for me and my family.

My most influential early faculty mentor was Kober Medalist Dr. James Wyngaarden. I had come to know Jim while I was a fellow with Jay Seegmiller since our scientific interests were similar. During my senior residency year at the MGH, I considered several academic positions and decided to go to Duke where Jim had just returned from Penn to succeed Gene Stead as Chair of Medicine. I remember well, on my first recruiting visit to Duke, Jim's plans for a new research building to be constructed just outside his office. He proudly laid out these plans on his conference table so he could show me the space I would occupy. My recollection is that he also pointed from his office window to a site where the building was to be built. I accepted his faculty offer and a few months later, Lois and I arrived with our three young daughters, and I was ready to start. Imagine my shock, despite my totally unrealistic expectations, when there was no building, or even evidence that it was a construction site, on that grassy hill just outside his office. To make a long story short, Jim provided far more and far better space than we had ever discussed in my consideration of the position. Even more importantly, his support throughout my 7 years at Duke could not have been stronger. I believe it was this experience that led me to understand the importance of more than exceeding commitments made to prospective faculty in the recruitment process as well as the critical role the Department Chair should play in mentoring junior faculty.

The fifth person I wish to mention who has been a great role model and mentor for me, especially through my more recent years in a senior administrative role at a complex institution, is Dr. P. Roy Vagelos. My first contacts with Roy were in the mid-1960s when Roy was teaching a course at the NIH on fatty acids and intermediary metabolism. However, I really came to know Roy well when I took the administrative position at Penn in 1989. Roy was a Trustee at Penn and he was later to become Chairman of the Board of Trustees. In addition, in 1992, I became a member of the Board of Directors at Merck where Roy was serving as the Chairman and CEO. Here again in my life, I had the unique opportunity to interact, first-hand and frequently, with one of the most outstanding leaders of our contemporary world. I find it impossible to summarize in a few words all he meant to me except to say that he is a brilliant man of the highest integrity from whom I have learned so much.

Hence, my professional career was molded not only by the outstanding mentorees with whom I have worked, but also by my experiences with my Dad and some of the giants in American medicine. Am I unique in having had this wonderful opportunity to work with such outstanding people? I think not. I suspect each of you in this room, and, indeed, each member of the Association can tell a similar story of giants by whom they have been mentored and, for many, this may have been as critical to their success as this has been for me. Perhaps a more important question is whether those giants will be there for future generations. I would answer with a resounding "yes." Their names will be different, of course, and what they do even may be different, but they will be there and they will be no less important in the future than they are today.

I do have serious concerns, however, about the flip side of this issue, which I will call the "black hole" of academic medicine for the sake of a better term. Even today there are many talented aspiring young stars who do not have the good fortune to link with the right mentor. In this case, they may lose the magnificent opportunity to pursue a successful academic career and their potential contributions to science will be lost. I attribute this to a series of fatal flaws at the institutional level which we, as leaders in our own academic institutions, could and should do more to correct. However, all will not be lost. These special people will be successful and important contributors in whatever they chose to do in medicine. They will provide great care to their patients. Most will be important leaders in their community. Some will go on to provide strong leadership and to make memorable contributions in the broader field of health care services, industry, and even in politics.

Enough for now. Again, my deepest appreciation to all of you who have meant so much to me and a final thanks to the Association for this wonderful recognition. Thank you very much. 